\title{
Intelligent Baby Monitoring System
}

\author{
Mr.A.R.Telepatil, Miss.P.P.Patil, Miss. S.S.Yajare, Miss.S.R.Jadhav
}

\begin{abstract}
Implemented project work deals with a intelligent baby monitoring system. This system is helpful for busy parents to ensure care and safety of their babies with use of advanced technology. Implemented work going to detect baby's crying sound, motion as well as live streaming of baby position in cradle. The live streaming of babies position and activities are displayed on display unit which helps parents to have continuous baby monitoring. The implemented work deals with design and development of a baby cradle using raspberry pi B+ as control unit. The different sensors like rain drop sensor, condenser MIC and camera are used to assist baby monitoring and are interfaced with the raspberry pi B+. The baby sound like crying is detected by condenser MIC. Live streaming is done by the pi camera. Baby's urine is detected by wet sensor and SMS will be sent to parents. The result obtained from the designed work shows the easier and convenient way of baby monitoring for busy parents.
\end{abstract}

Index Terms - Baby Monitoring System, Raspberry Pi, Pi Camera.

\section{INTRODUCTION}

The baby cradle is used to make sleep and soothe to a baby. Conventional cradle does not electronically equip such like battery or adapter to automate the cradle. In Addition to that, these kind of conventional cradle is used in villages areas or non-developed cities due to its low prices. These designated cradle need a manpower to take care of child .However a child may not be safe and feel comfortable in the conventional cradle. Thus, there is a scope to automate the cradle to take care of child. Besides, there are extra features or function is provided by the newly automatic cradle that is beneficial for parents. In the present world people are very busy in their professional life so they do not get ample time to take care of their infants. It will be very difficult control the babies and if someone is hiring professional to take care of their infants. It may increase the monthly expenses. Moreover, in today, life it is very hard to even for the homemakers (mummy) to sit nearby their babies and sooth them whenever they feel uncomfortable. The baby monitoring system is a kind of alarm system which can detect babys movements and activities and can convey the message about the condition of babies to the concerned authority via

Manuscript revised June 9, 2019 and published on July 10, 2019

Mr.A.R.Telepatil, Department of Electronics and Telecommunication Engineering, D.K.T.E's TEI, Ichalkaranji, Maharashtra

Miss. P.P.Patil, Department of Electronics and Telecommunication Engineering, D.K.T.E's TEI, Ichalkaranji, Maharashtra

Miss. S.S.Yejare, Department of Electronics and Telecommunication Engineering, D.K.T.E's TEI, Ichalkaranji, Maharashtra,

Miss. S.R.Jadhav, Department of Electronics and Telecommunication Engineering, D.K.T.E's TEI, Ichalkaranji, Maharashtra, mobile or even a display. Monitoring a baby continuously is really a tough job as well as it is not possible for the parents to carry out their babies all the time with them especially while working. In proposed system intelligent baby monitoring framework has been designed and developed using raspberry pi $\mathrm{B}+$ as control unit. The different sensors like rain drop sensor, condenser MIC and camera are used to assist baby monitoring and are interfaced with the raspberry pi $\mathrm{B}+$. The baby sound like crying is detected by condenser MIC. Live streaming is done by the pi camera. Baby's urine is detected by wet sensor and SMS will be sent to parents. The result obtained from the designed work shows the easier and convenient way of baby monitoring for busy parents.

\section{LITERATURE SURVEY}

Aslam Forhad Symon et al. [1] designed baby monitoring system to detect baby's activities like motion and cry sound. This system is accomplished with display unit, buzzer and camera module. Whenever baby motion or cry is detected, camera module is turned on to display baby motion on display unit and buzzer to indicate baby's cry Detection. System proposed in [2] is designed using raspberry pi 3, camera, wet sensors, sound sensor, PIR sensor, sound sensor, DC motor and SMS module. This system encloses the different features like camera monitoring, automatic swinging of cradle when baby cries, sensing the wetness of baby's bed, monitoring presence of baby in the cradle. Message about baby's cry, wetness in bed and absence of baby in the cradle are sent to parent's mobile number to intimate them about their baby.

Savita P. Patil et al. [3] presented a baby monitoring system based on GSM network. This system monitor's body's health parameters like temperature, moisture, pulse rate and movement and deliver these measured parameters on the parent's mobile using GSM network. System presented in [4] includes reminder system as important feature in baby monitoring activity. It conveys measurements of various parameters to the parents with an alarm triggering to initiate proper actions. Using this feature, parents or caretakers can set reminder about feeding time and vaccination date.

Framework of the proposed in [5] deals with developing a smart electronic cradle to convoke all the data to assist the baby and to bridge the gap between the parents and the infant. The main nonpartisan of the system is to create a bed time ritual, lull the baby to slumber, assist the baby and to provide a healthy environment. Prototype model presented in [6] is a configuration of a programmed cradle with the assistance of a PIR sensor and android app. PIR sensor detects the movement of infant. Cradle swings are controlled via voice command through mobile app. The cradle additionally incorporates a wet sensor which will caution the folks or the Attendant/sitter for bunk wetting of the infant. 
[7] Presents the design and implementation of cradle system that swings the baby cradle automatically when baby cries. The system has inbuilt alarm that indicates two conditions - first when the mattress is wet, which is an important parameter to keep the baby in hygienic condition, second when baby does not stop crying with in a stipulated time, which intimated that baby needs attention. The equipment proposed in [8] includes a motor, sensors, and oscillating carriage. The electric powered motor will actuate the links by shaft and the links actuates the bed in a constant speed which is attached to the carriage.

\section{III.SYSTEM DESIGN AND IMPLEMENTATION}

\subsection{Hardware Implementation:}

\subsubsection{Raspberry Pi and Pi camera:}

The Raspberry Pi 3 Model B+ as shown in fig. 3.1 (a) is the latest product in the Raspberry $\mathrm{Pi} 3$ range, boasting a 64-bit quad core processor running at $1.4 \mathrm{GHz}$, dual-band $2.4 \mathrm{GHz}$ and $5 \mathrm{GHz}$ wireless LAN, Bluetooth 4.2/BLE, faster Ethernet, and PoE capability via a separate PoE HAT. The Raspberry Pi Camera Board as shown in fig 3.1(b) plugs directly into the CSI connector on the Raspberry Pi. It's able to deliver a crystal clear 5MP resolution image or $1080 \mathrm{p}$ HD video recording at $30 \mathrm{fps}$. The module attaches to Raspberry Pi, by way of a 15 Pin Ribbon Cable, to the dedicated 15-pin MIPI Camera Serial Interface (CSI), which was designed especially for interfacing to cameras. The CSI bus is capable of extremely high data rates, and it exclusively carries pixel data to the $\mathrm{BCM} 2835$ processor.

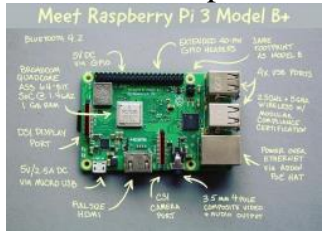

(a)

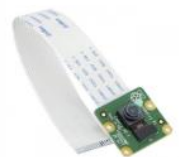

(b)
Fig 3.1 (a) Raspberry Pi 3 B+ Module Fig 3.1 (b) Pi Camera

\subsubsection{Condenser MIC and Wet sensor}

Sound Detection Module is shown in fig 3.2 (a) .It is a Single channel signal output Sensor. The output is effective to the low-level sound signal with good fidelity, when there is sound, outputs low level and signal light. Condenser MIC module is used to detect the baby's sound. When baby cries condenser MIC detects the sound and gives output to the controller and detection of sound is displayed on screen. The rain sensor module shown in fig 3.2 (b) is an easy tool for wetness detection. It is connected to $5 \mathrm{~V}$ power supply, the LED will turn on when induction board has no water drop, and DO output is high. When dropping a little amount water, DO output is low, the switch indicator will turn on. Brush off the water droplets, and when restored to the initial state, outputs high level.

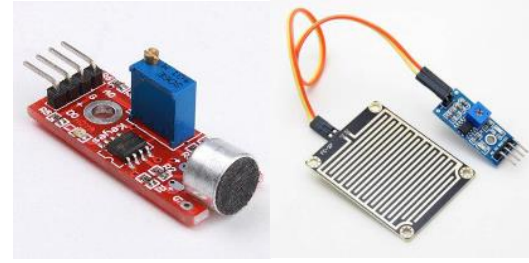

(a)

(b)

Fig 3.2 (a) Condenser MIC Fig 3.2 (b) Rain drop sensor

\subsubsection{Motor, Motor driven IC and Gear:}

100RPM Centre Shaft Economy Series DC Motor is high quality low cost DC geared motor. The L293D devices are quadruple high current half-H drivers. The L293D is designed to provide bidirectional drive currents of up to $1 \mathrm{~A}$ at voltages from $4.5 \mathrm{~V}$ to $36 \mathrm{~V}$. The $\mathrm{L} 293 \mathrm{D}$ is designed to provide bidirectional drive currents of up to $600-\mathrm{mA}$ at voltages from $4.5 \mathrm{~V}$ to $36 \mathrm{~V}$. Gear is used for converting circular motion into forward and backward (linear) motion with help of specific setup. DC motor with motor driver IC and gear is as shown in figure 3.3 (a), (b), (c) respectively.

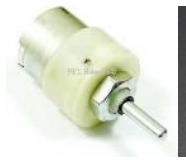

(a)

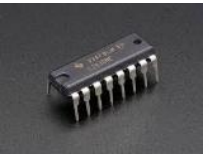

(b)

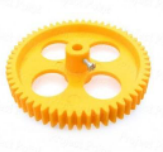

(c)
Fig 3.3 (a) DC motor Fig 3.3 (b) IC L293D

\section{Plastic gear}

Fig 3.3 (c)

Complete hardware setup oh implemented work is as shown in figure 3.4 .

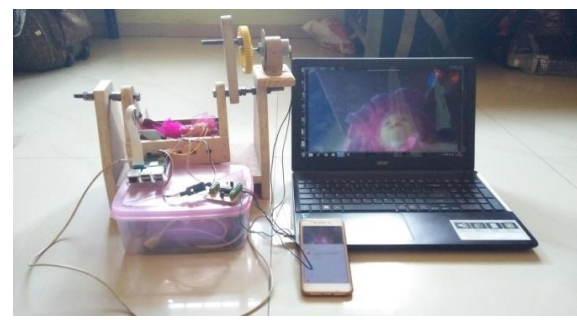

Figure 3.4 Complete hardware view of implemented system

\subsection{Software Implementation:}

Step 1: Initially GPIO pins are scanned.

Step 2: Camera turned on.

Step 3: If input from firebase is " $\mathrm{f}$ " then output at GPIO pin 21 and 20 is True and False resp.

if input from firebase is ,,se then output at GPIO pin 21 and 20 is False and False.

Step 4: If sound is detected then step 5 is carried out and if urine is detected step 6 is carried out.

Step 5: Message is displayed on screen.

Step 6: Message will be sent to parents mobile.

The flow of operation for implemented work is as shown in figure 3.5 


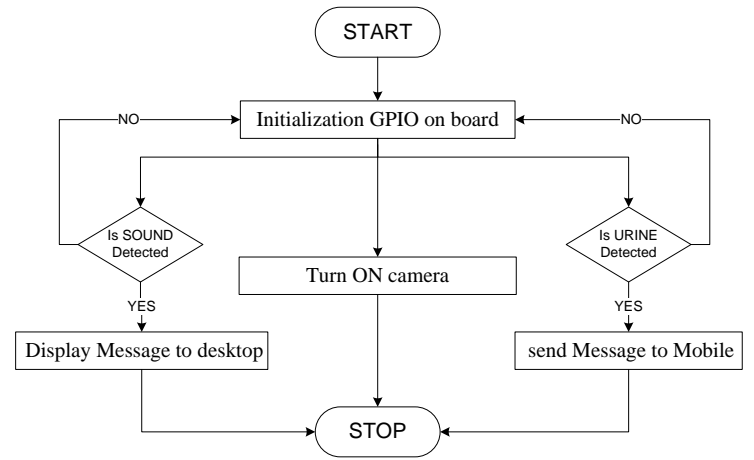

Figure 3.5: Flowchart of operation

\section{RESULTS}

The implemented project work is capable of sending a live video stream of the baby using camera to webpage, accessible through both mobile phone and laptop. Live steaming is as shown in figure 4.1

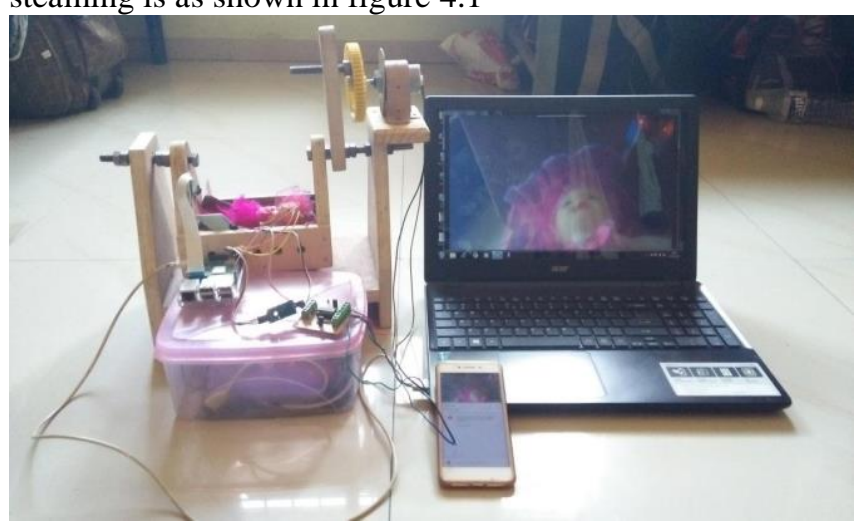

Figure 4.1: Live Streaming

If urine is detected notification is sent to parents to change the diaper. Twilio software is used to send notification. Notification result is as shown in figure 4.2

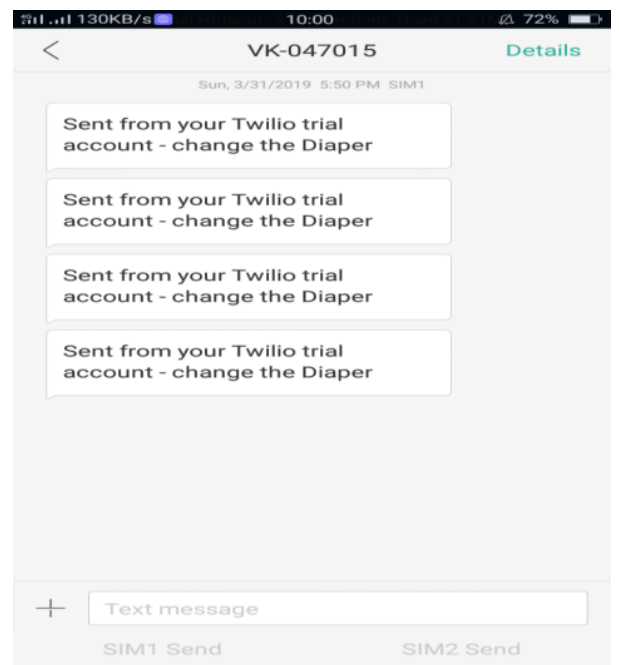

Figure 4.2: Notification system

\section{CONCLUSION AND FUTURE SCOPE}

\subsection{Conclusion:}

The electronic baby cradle is the finest solution for today's parents who cannot find the sufficient time for their babies. This intelligent baby cradle would let the working mother to do household works besides taking care of baby at the same time. It is economical and user friendly. The intelligent baby cradle can be used in hospitals and home. It is very useful for working parents and hospitals to take care of babies.

\subsection{Future scope:}

In future we can add more features to make more efficient and user-friendly. The feature we can add to this device such rotating toy and the sound detector to detect sound of the baby could be added to enhance the system features. By using machine learning it is possible to detect only baby's voice. We can add music or lullaby which can entertain baby. With the development of technology daily routine has been eased for the parents along with the baby care.

\section{REFERENCES}

[1] Aslam Forhad Symon, Nazia Hassan, Humayun Rashid, Iftekhar Uddin Ahmed, S M Taslim Reza, "Design and Development of a Smart Baby Monitoring System based on Raspberry Pi and Pi Camera",4th International Conference on Advances in Electrical Engineering pp 117-122, September 2017.

[2] S.Srikanth, P.Ramya, M.Satheesh, G.Thomas Philip and K.Vineetha "Smart Baby Cradle System",International Journal of Advances in Scientific Research and Engineering,Volume 4, Issue 3, pp 51-60, March - 2018

[3] Savita P. Patil and Manisha R. Mhetre, "Intelligent Baby Monitoring System", ITSI Transactions on Electrical and Electronics Engineering, volume 2, Issue 1, pp.11-16, 2014.

[4] Shreelatha, Shreya Pai, Sonal Cynthia Pereira, Tanya Nicole, Ms Ushadevi A., “ Advanced Baby Monitor" International Journal of Internet of Things ,pp 51-55, June 2017.

[5] I.Natheera, S.Sundaravadivel, N.L.Visakan,S.Viswanathan and M.Vivekkumar, "Smart Cradle", Asian Journal of Applied Science and Technology (AJAST), Volume 2, Issue 2, Pages 291-300, April-June 2018.

[6] P.B. Patel, Sudhir Ticku, Suraj Darunde, "Automation In Baby Cradle Bed",International Journal of Advance Research in Science and Engineering,vol ,issue 4,april 2018

[7] Misha Goyal,Dilip Kumar, "Automatic E-Baby Cradle Swing based on Baby Cry", International Journal of Computer Applications (0975 8887) Volume 71- No.21, June 2013.

[8] Tushar P. Patekar, Pooja S. Dawale, Pooja A. Jaiswal, "Design and Fabrication of Automatic Baby Cradle System", International Research Journal of Engineering and Technology (IRJET) Volume: 05,Issue: 02,Feb-2018

\section{AUTHORS PROFILE}

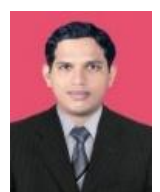

Mr.A.R.Telepatil received his Master's Degree in Electronics Engineering from Shivaji University Kolhapur in 2009. Presently he is working as Assistant Professor in D.K.T.E.'s Textile and Engineering Institute, Ichalkaranji. His areas of interests are Embedded System, Image Processing and Communication Engineering.

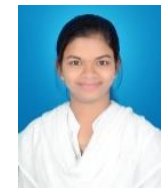

Miss. P.P.Patil received her Bachelor's Degree in Electronics and Telecommunication Engineering from Shivaji University Kolhapur in 2019. 
International Journal of Research in Advent Technology, Vol.7, No.6, June 2019

E-ISSN: 2321-9637

Available online at www.ijrat.org

Miss. S.S.Yejare received her Bachelor's Degree in Electronics and Telecommunication Engineering from Shivaji University Kolhapur in 2019.

Miss. S.R.Jadhav received her Bachelor's Degree in Electronics and Telecommunication Engineering from Shivaji University Kolhapur in 2019. 